Corrigendum

\title{
Corrigendum to "Protective Effects of Soy Oligopeptides in Ultraviolet B-Induced Acute Photodamage of Human Skin"
}

\author{
Bing-rong Zhou $\mathbb{D}^{1},{ }^{1}$ Li-wen $\mathrm{Ma},{ }^{2}$ Juan Liu, ${ }^{1}$ Jia-an Zhang, ${ }^{1}$ Yang Xu, ${ }^{1}$ Di Wu, ${ }^{1}$ \\ Felicia Permatasari ${ }^{D}{ }^{1},{ }^{1}$ and Dan Luo ${ }^{1}{ }^{1}$ \\ ${ }^{1}$ Department of Dermatology, The First Affiliated Hospital of Nanjing Medical University, Nanjing 210029, China \\ ${ }^{2}$ Drum Tower Hospital, Medical School of Nanjing University, Nanjing, China \\ Correspondence should be addressed to Bing-rong Zhou; bingrong.2002@163.com
}

Received 5 December 2017; Accepted 12 December 2017; Published 10 January 2018

Copyright (C) 2018 Bing-rong Zhou et al. This is an open access article distributed under the Creative Commons Attribution License, which permits unrestricted use, distribution, and reproduction in any medium, provided the original work is properly cited.

In the article titled "Protective Effects of Soy Oligopeptides in Ultraviolet B-Induced Acute Photodamage of Human Skin" [1], the affiliation of the second author was missing. The corrected authors' list and affiliations are shown above.

\section{References}

[1] B. R. Zhou, L. W. Ma, J. Liu et al., "Protective effects of soy oligopeptides in ultraviolet B-induced acute photodamage of human skin," Oxidative Medicine and Cellular Longevity, vol. 2016, Article ID 5846865, 13 pages, 2016. 


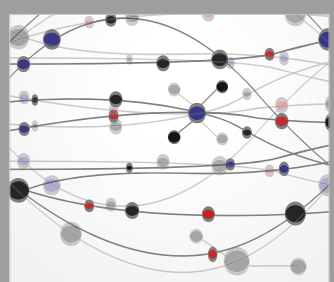

The Scientific World Journal
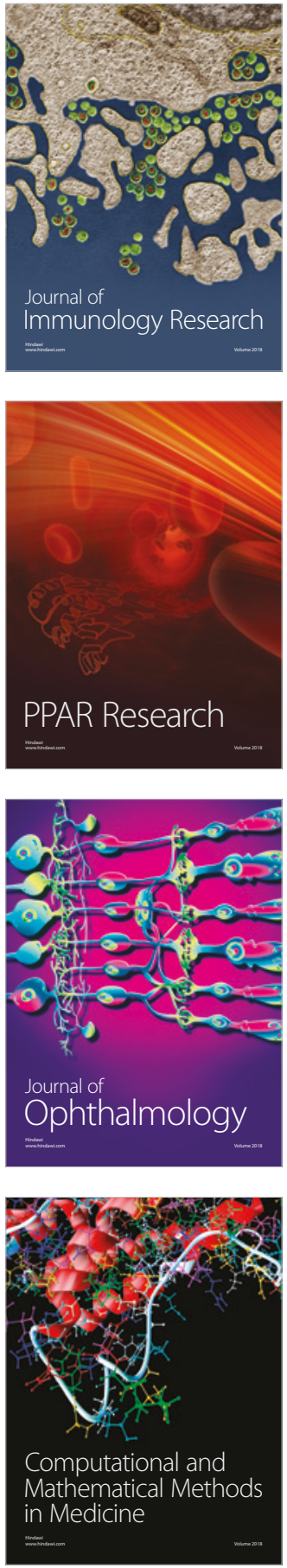

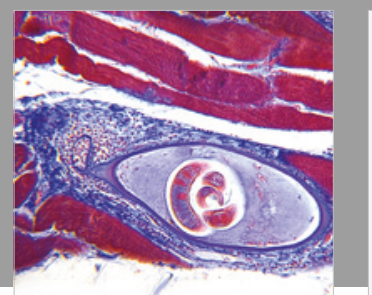

Gastroenterology Research and Practice

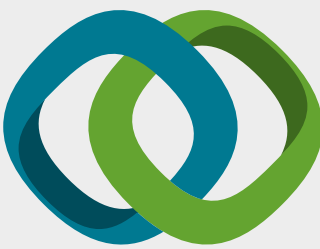

\section{Hindawi}

Submit your manuscripts at

www.hindawi.com
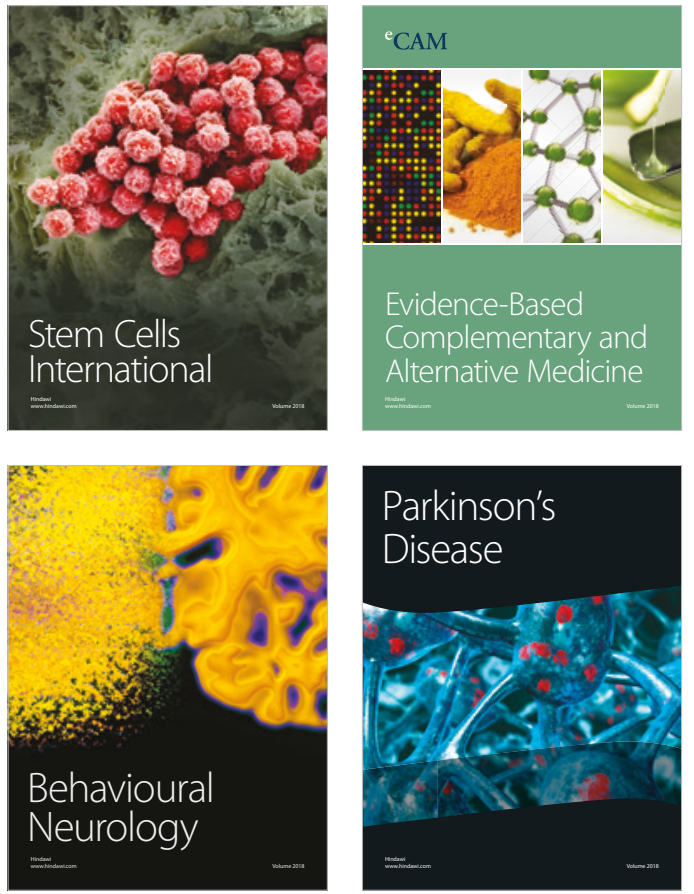

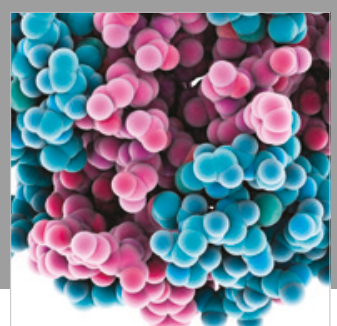

ournal of

Diabetes Research

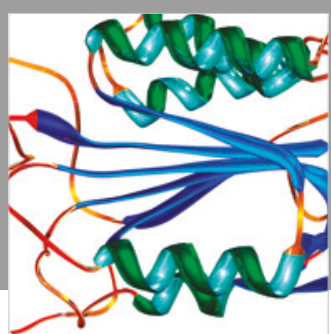

Disease Markers
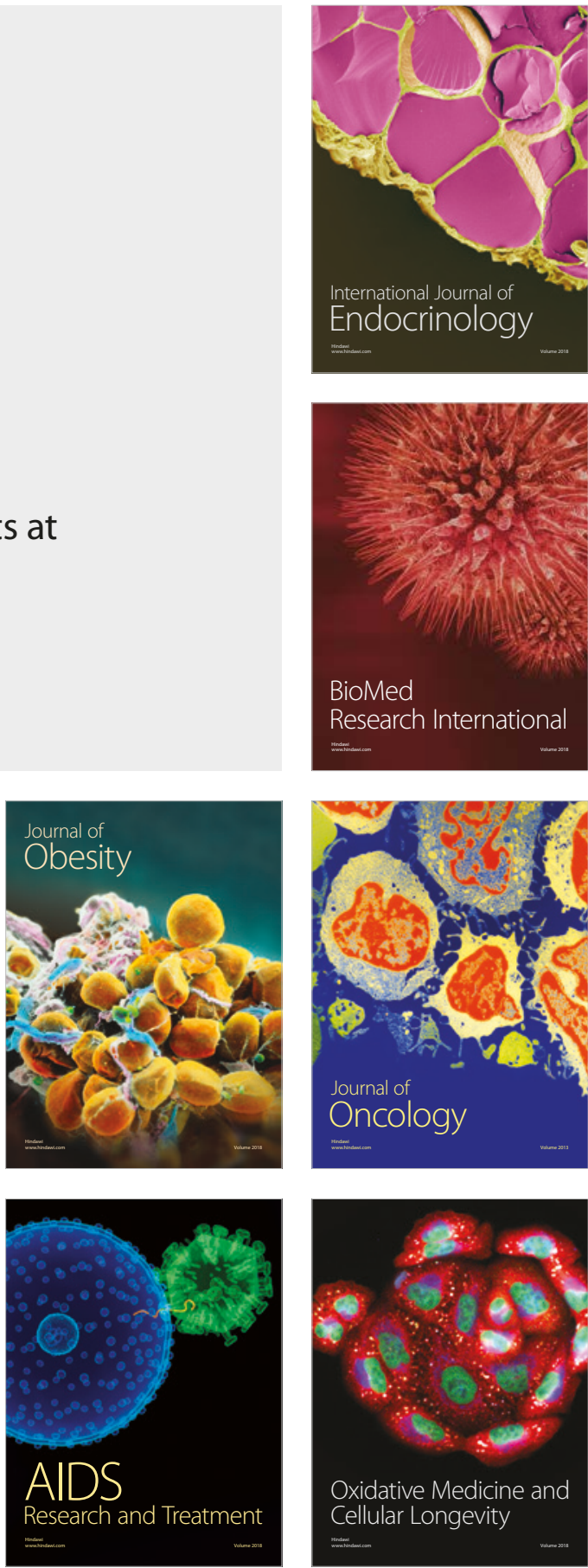